\title{
Re-Thinking a Structural Model for M-Phone Paying among South African Consumers
}

\author{
Dlodlo N. \\ Vaal University of Technology, South Africa \\ nobukhosid@vut.ac.za
}

\begin{abstract}
Contemporary payment systems have transformed global businesses extensively. Nevertheless, despite its vast prospects, the widespread utilisation of mobile phone technology for payment transactions (m-phone paying) and reproduction of pecuniary structures has only been hemmed in among a small number of markets. The proliferated reliance on mobile payment services has not been witnessed universally, suggesting that even success stories are still ambivalent and as a result, cannot be easily replicated. This paper is intended to address this issue by evaluating the determining factors towards the continued use of $\mathrm{m}$ phone payment services by existing South African customers. The research model was tested using SMART PLS 3, upon examining the antecedents of users' intentions toward embracing the emerging mobile phone in commercial transactions. A cross-sectional study was performed on a sample of 474 consumers, wherein security and usefulness were validated as having significant and direct effects on consumers' attitude towards m-phone paying, of which the latter influences future intentions. The relevance of customers' future intentions towards m-phone paying was established, thereby sanctioning the idea to include the variable as a proxy for actual usage in technology adoption research. This study provides sound reason for cumulative research that seeks to refine novel models of technology acceptance even further. For marketers and mphone technologists, understanding the key determinants is vital towards the upgrade and implementation of $\mathrm{m}$-phone payment services. In lieu of this, delivering $\mathrm{m}$-phone applications and payment services that achieve high usage, value and consumer laudation will be an inevitable boon.
\end{abstract}

Keywords: Mobile, m-phone paying, consumers, South Africa

\section{Introduction}

Mobile telephony and the Internet itself are of such transformative significance to contemporary society and as such, have been the target of many researches (Abrahão, Moriguchi\& Andrade, 2016:221; Overbr, 2014; Diniz, Albuquerque \&Cernev, 2011; Cernev, 2010; Dahlberg, Mallat, Ondrus\&Zmijewska, 2008; Rao \&Troshani, 2007). Generally, mobile devices are considered portable, ubiquitous technologies of which users have a close personal relationship with the physical device involved (Zhong, 2009). Mobile devices, especially the smartphone, remain the centrepiece in which payments could be initiated, apart from being the flagship instrument in the conflux between communication and entertainment functions (Rao \&Troshani, 2007). Companies related to the sectors of communication and payments are focused on good business opportunities that are a result of the fulfilment of such needs (Overbr, 2014). Among the services delivered using mobile phone devices such as access to information, entertainment and transaction permissions (ticket bookings, banking, money transfers, tracking orders and verification of banking account records), there is a trend called mobile payments (hereinafter referred to as m-phone paying).

Broadly speaking, m-phone paying draws from the m-payment notion, which is defined as "a process in which at least one phase of the transaction is conducted using a mobile device capable of securely processing a financial transaction over a mobile network or through various wireless technologies" (Ghezzi, Renga, Balocco\&Pescetto, 2010:5). Equally, Dahlberg et al. (2008:166) designate mobile payment to be the "payment for goods, services and bills with a mobile device while taking advantage of wireless and other communication technologies". These two definitions encapsulate all types of mobile devices, including mobile phones and personal digital assistants (PDA). Liu, Kauffman and Ma (2015) extend the definition to encompass other monetary exchanges, including banking. Nevertheless, Donner et al. (2008:319) enumerate more related concepts in the field. For instance, the scholars pointed out that $\mathrm{m}$-banking, m-payments, $\mathrm{m}$ transfers and $\mathrm{m}$-finance refer to a communal practise that enables the use of mobile phones by individuals for commercial practises. However, to ensure lucidity, the scholars singled out mobile money, mobile transfer and mobile banking as systems involving simple direct consumer-bank relations. This could encapsulate the checking and storage of value in bank accounts that are linked to mobile phones. Notwithstanding this, mobile phone paying is a process comprising triple players, namely the consumer, commercial retailer and 
the bank (Olivier et al., 2016). Resultantly, the mobile device has transcended into a definitive method of payment as it permits an all-inclusive convergence between the consumer, consumer's bank and the merchant by using a financial switch (Ondrus\&Pigneur, 2007). The focus of this research is exclusively on payments that are conducted using the mobile phone alone, in accordance with previous definitions and distinctions presented. Thus, while m-phone paying includes the payment operations linked to mobile transactions and mobile money, the practise has the advantage of being neutral and universal and is thus considered well-matched for fulfilling the goals of this study.

When technological innovations are associated with the mobility of individuals, a trajectory is evident on the social and professional development of societal members (O'Reilly, Duane \& Andreev, 2012). For instance, the extensive usage of mobile phones and the uninterrupted closeness of the devices to the users render them suitable for m-phone payment scenarios. This positions the real commercial significance of mobile phones at the fore. Duane, O'Reilly and Andreev (2014) attest that there are several benefits from conducting commercial payments using mobile devices. Relatedly, the use of mobile phones for payment transactions eliminates the need to use cash (Pham \&Ho, 2015), thereby offering convenience and speed (Teo, Tan, Ooi, Hew \& Yew, 2015). In addition, the rapid transfer of secure data between devices is made possible (Leong, Hew, Tan \& Ooi, 2013). According to the Gartner Group (2012), the value of transactions conducted through mobile devices exceeded $\$ 171.5$ billion in 2012, across all global markets. In particular, the practise of sending and receiving money has proven to be a success in sub-Saharan Africa, with approximately 16 percent of adults reported as having engaged in the practise in 2012. Furthermore, a global media report revealed that the proceeds realised from mobile payments is projected to surpass USD721 billion in 2017 (Statistica Corporation, 2015), thus rendering m-phone paying an imperative for completing financial transactions. In this vein, m-phone paying could be considered a key enabler of mobile commerce, since such payment initiation mechanisms are the anchor for convenient mobile commerce transactions.

Accenture's (2014) media intelligence report predicts that the mobile payments volume in South Africa will reach over R83 billion by 2017 with 60 percent of South Africans planning to make a commercial payment of sorts, using their mobile phone. Even so, actual m-phone subscribers are fickle, demonstrating erratic behavioural trends that are not strategically viable for the success of a mobile device as a platform for initiating transactions. Nevertheless, since mobile phones are readily available (Dinizet al., 2011), m-phone paying could be the instrumental solution for overall financial inclusion in South Africa. This could have an unprecedented effect on reaching rural communities and other individuals with poor access to mainstream financial services, owing to the lower costs of conducting transactions. Thus, if commercial transactions were to be conducted on mobile phones, they could relatively easily and cheaply, reach people who are excluded presently. The contribution of this study is twofold. First, the paper aims to identify the direct and indirect effects of various antecedent variables towards m-phone paying. This objective is clarified by complementing earlier research that underscores the salience of the technology acceptance model (hereinafter referred to as TAM). The second objective of this work pertains to complementing the findings of earlier studies, thereby expanding cumulative knowledge regarding the determinants of m-payment future intentions within a South African context.

\section{Literature Review}

Howard and Sheth (1969) explain consumer behaviour based on rationality, comprising the consumer's organisation of decision-making processes as well as the external impacts that stimulate an individual to purchase. Drawing from this, a process view is presented whereby both commercial and social stimuli act as inputs that promote individual reactions regarding purchase choices and behavioural decisions. Such stimuli often comprise the expectations generated by the efforts of marketers, pricing, quality and ease of use among others (Schiffman, Kanuk \& Wisenblit, 2010). Such stimuli compel consumers to collect and process information about the available goods and services while synthesising the learning step. The individuals are then able to evaluate all possible alternatives using a set of heuristics implying that a mental pre-disposition is aroused. While the ensuing attitude may be favourable and/or unfavourable, consumers' feelings linked to both environmental and individual influences culminate into a decision or intent to participate in specified acts. 
This article forms part of the continuing scholarship on consumer behaviour in which different authors have sought to explain the behaviour of individuals in the face of technological innovations through varied theories and models. Scholars such as Abrahao et al. (2016) have endeavoured to identify the most relevant factors in the adoption of new technologies. Ideally, a model that is useful in both a predictive and explanatory capacity is required by both researchers and practitioners to enable the identification of formulae of corrective measures for that particular system to be acceptable.

The TAM sets the undertones for this study as it has been applied universally, in research concerned with information systems (Abrahao et al., 2016; Jeong \& Yoon, 2013). The TAM is used widely owing to its simplicity and parsimony (Jeong\& Yoon, 2013:34). In addition, the TAM seems to provide a better foundational theory for this study owing to its specificity in addressing the antecedents of technology use, as compared to the theory of reasoned action (TRA) as well as the theory of planned behaviour (TPB), which generally are considered generic human behaviour theories. Within this vein, Davis, Bagozzi and Warshaw (1989:985) postulate that a fundamental purpose of TAM is to "provide a basis for outlining the impact of external factors on internal beliefs, attitudes and intentions of technology users". As such, TAM proposes that two particular beliefs, namely perceived usefulness and perceived ease of use are the primary enablers of new technology usage. These two variables influence intention to use a system, of which the latter is associated with actual use.

Davis et al. (1989) define perceived usefulness as "the customer's subjective belief that using a particular system would enhance his or her job performance in an organisational context". This definition provides direction regarding the beneficence afforded by new technologies. In the context of online platforms, perceived usefulness indicates that the use of a given technology might be useful for someone to achieve a particular result (Abrahao et al., 2016). In which case, along mobile contexts this would include the extent to which the consumer believes that the payment process will offer access to useful information and will speed up transactions.On the other hand, perceived ease of use refers to "the individual's perception that using a certain system is effortless or simply easy to do" (Daviset al., 1989:986). Since mobile phones come with a number of restrictions, ease of use inevitably becomes a vital enabler of payment services performed along this platform. This is because mobile applications compete with traditional payment solutions on key aspects such as clear symbols, function keys and graphic display. As such, this construct encapsulates consumers' perceptions regarding the easiness of m-phone paying, rather than the actual features of the mobile phone, per se. For this reason, ease of use has been validated as having a positive influence on the acceptance of new technology.For all of the abovementioned reasons, both usefulness and ease of use are incorporated in this study as underlying antecedents. Therefore, given that $\mathrm{m}$-phone paying is considered an innovation within existing payment systems of different countries, the benefits afforded by mobile phones are related closely to its advantages. Akin to the aforementioned determinants, security was incorporated as a third determinant since $\mathrm{m}$-phone paying involves detail about transactions that could be personal and sensitive to users (Duane et al., 2014).

Oliveira, Thomas, Baptista and Campos (2016:412) identify security as a future research direction in mobile technology related works, thereby augmenting the scope of this study. According to Mallat (2007:416), subjective security refers to the degree to which a person believes that using a particular payment procedure would be secure. Generally, consumers are concerned about issues relating to confidentiality of their personal details, verification and unauthorized access to user data by unauthorized persons (Kim, Mirusmonov \& Lee, 2010:86). Since the applications that operate on the majority of mobile devices function on an open network with no direct human control over individual transactions, it is necessary to develop infrastructure that is hardened against security breaches. A secure payment system should protect consumers against fraudulent activities and further support consumer privacy.

The seminal work by Fishbein (1963) predicated that attitudes reflect people's favourable or unfavourable feelings toward a given behaviour. By implication, the attitudes of consumers mature progressively, consistent with product or service experiences. Research has shown that attitude is an essential pre-requisite of the intention to develop a skill associated with technology use (Fishbein \& Ajzen, 1975). Notwithstanding this, other scholars allude that attitude is a multi-dimensional construct comprising a cognitive, emotional and conative or behavioural dimension (Schiffman et al., 2010). The knowledge, perceptions and beliefs that 
are acquired during use, denote the cognitive component. Similarly, affect (emotional) refers to the individual's feelings and preferences while the conative component is the behavioural intention or inclination to perform (or not) a particular action. The main criticism against the triple-perspectives view is related to the lack of independent measurements of the tripartite set of dimensions. Furthermore, the majority of consumers only respond to the emotional component, which largely complicates the correct measurement of users' attitude (Abrahao et al., 2016). This paper proffers a one-dimensional (emotions) conception, whereby previous beliefs and experiences with $\mathrm{m}$-phone paying is an antecedent, while a user's willingness or conative component stands as a direct consequence of consumers' attitude. In this way, the study relocates the cognitive and conative components outside the conceptualisation of attitude while only the conative component is re-named 'future intentions to conduct m-phone paying' in this work.

Future intentions to conduct m-phone paying: Traditionally, Fishbein and Ajzen (1975:307) have conceptualised the behavioural intentions variable as "the degree to which a person formulates conscious plans to perform or not perform some futuristic behaviour". At this level, both personal and socially induced influences tend to propel individuals to behave in a particular manner. Consequently, Malhotra and McCort (2001:241) impress upon elements comprising the careful reasoning and conversion of individual plans into actionable goals based on experiences with a product, service or technology (Schiffman et al., 2010). While the construct has not been attended to by researchers in other instances, Miltgen, Popovic and Oliveira (2013) position the intentions variable as a type of behaviour that occurs and continues well after users have embraced mobile technology. Drawing from this, future intentions is nominated as the dependent variable in this research since intentions is a principal contributing factor towards definitive actions, albeit in futuristic circumstances. Consistently, several researchers have used intentions as a substitute for actual behaviour (Yu, 2012; Teo, Luan \& Sing, 2008; Kim, Chun \& Song, 2009; Ajzen, 1989). This approach shadows Solomon, Bamossy, Askegaard and Hogg (2006:157), who noted that there was an affirmative correspondence, in the direction of actual usage when quantitative surveys utilise an intention to use measure. In this study, future intentions is operationalised as the effort of making conscious plans to conduct commercial payments through the mobile phone, in future encounters.

Study hypotheses: The literature throws spotlight upon several validated works, thereby presenting the prospects to test a series of hypotheses in this work. Initially, as already alluded to, m-phone paying is of such a delicate nature since monetary instruments are deployed. Therefore, when consumers advance a positive perception of security and trust in the technology, confidence in the exchange relationship increases and further encourage open, substantive and influential information exchanges (Yousafzai, Pallister \& Foxall, 2009). Therefore, security is a "key element in consumers' decisions to adopt mobile payments" (Lin, 2011:256). Moreover, security is linked indirectly with the intentions variable, through attitude.This espoused path concurs with the finding by Meharia (2012) as well as that of Wang and Idertsog (2015). Therefore, it is anticipated that:

$\boldsymbol{H}_{1}$ : Perceived security has a direct and significant effect on attitude towards m-phone paying.

The usage of mobile phones for payments often is motivated by the usefulness of technology in fulfilling daily tasks (Kim et al., 2010). As such, the decision to conduct a payment transaction through the mobile phone will be evaluated by the consequences of such an act. To the time-poor consumer, convenience and compatibility with modern lifestyles is afforded while the merchants benefit from reduced costs per transaction owing to the diminution of brick and mortar branches. Revels, Tojib and Tsarenko (2010:76) established that perceived usefulness is an antecedent towards favourable attitude evaluations of a new technology. Erasmus, Rothmann and Eeden (2015), who attest that a customer will conduct m-payments based on the belief that the platform assists consumers to process tasks fittingly, support this relationship. Therefore, the inference is that when consumers find m-payments both valuable and beneficial for their everyday needs, they are likely to develop positive affective evaluations towards the payment solution. Therefore:

$\boldsymbol{H}_{2}:$ Perceived usefulness has a direct and significant effect on attitude towards m-phone paying.

While m-phone paying could offer immense benefits to users, it is possible that usefulness of the platform could be eclipsed by the effort required to process transactions; all the more reason for $\mathrm{m}$-phone paying to be an effort-free activity. Put simply, consumers will be attracted to the notion of conducting payments by mobile phone if the process is user-friendly. This study is predicated upon the assumption that an easy to use 
m-phone paying service could influence the intention to use mobile payments, albeit through the attitude construct. Therefore, it is stated thus:

$\boldsymbol{H}_{3}$ : Perceived ease of use has a direct and significant effect on attitude towards m-phone paying.

A favourable attitude is formed after perceiving benefits and risk-reduction outcomes associated with conducting payment transactions on the mobile phone. Such evaluations determine future intentions, which most likely ascertain users' acceptance of m-payment technology and related services (Choi, Lee \& Ok, 2014). Similarly, Hsiao and Chang (2013) concede that technology users' participation in mobile-based transactions is affected by both rational decisions and affective commitment. Therefore, this study asserts that:

$\boldsymbol{H}_{4}$ : Attitude has a direct and significant effect on future intentions towards m-phone paying.

Problem under investigation: While South Africa is among the top five markets with a high mobile payments readiness score of 29.1, success of the platform is still mediocre (Grubb, 2012). This suggests that the country has not developed adequate capacity yet, for the broad diffusion of mobile technologies across the national continuum. Nevertheless, Dlodlo (2015) refers to 'an elusive dream,' when portraying the degree of mobile paying advancement in the country. This is the current state of affairs; regardless of the fact that acceptance is a key issue that provides direction as to whether consumers will proceed to conduct m-phone paying in forthcoming instances. According to Oliviera, Baptista and Campos (2016), extensive publication effort and documented empirical works exist in the area of Internet banking, in comparison with other systems in the financial sector. Nevertheless, some authors (Slade, Williams, Dwivedi \& Piercy, 2014) contemplate that scientific enquiries into the espousal of mobile phone services for commercial reasons are in their early stages. Moreover, the previous lustrum paints a picture of scarce publications on mobile phone payments (Leong et al., 2013; Slade et al., 2014; Tan, Ooi, Chong \& Hew, 2014) within top tier journals. Interestingly, the aforementioned referred works advocate for more country-specific studies in this area. Furthermore, quantitative research focusing on mobile phone technology in South Africa is rudimentary and does not employ modelling techniques to test and prove hypotheses.

\section{Methodology}

Data were collected from a cross-section of participants, using the quantitative research approach. The motivation for following a quantitative approach was in the thoroughness and bias-free nature with which the methodology is applied (Malhotra, 2010).

Research instrument: The measures applied in this research were acquired from previous studies. However, there was need to substitute the words ' $m$-phone paying', to ensure consistency with the unit of analysis and goals of this research. A structured questionnaire was chosen as a measuring instrument as it is simple to administer and reduces the variability in the results thereby enhancing generalisability (Malhotra, 2010). The structured questionnaire comprised categorical data (gender, age, ethnicity, occupation, education and income levels). In addition, the questionnaire comprised five items measuring perceived security adapted from Yousafzai et al. (2009). Scales used in the works of Schierz, Schilke and Wirtz (2010) and LiêbanaCabanillaset al. (2014), measured perceived usefulness (three items) and ease of use (four items). Moreover, four scale items relating to consumers' attitude towards $\mathrm{m}$-phone paying were gleaned from the studies of Schierz et al. (2010), while five scale items relating to consumers' future intentions towards m-phone paying were adapted from the studies of Lin (2011). The non-categorical data were anchored along a seven-point Likert scale of agreement, since an improved scale with numerous points presents the potential for abundance of information and greater reliability, whereas anything greater than seven points seemed impracticable for a study of this nature. Moreover, the scale is consistent with previous scholars.

Participants and sampling: The southern Gauteng province of South Africa is the geographic location of the sample. Both male and female users of mobile phone payment services who are 18 years and older were included in the study. However, lack of a reliable and accurate list of participants meant that the study was amenable to non-probability based sampling procedures. More specifically, the snowball sampling technique was used as it has been cited as very beneficial, in the absence of a suitable sampling frame (Churchill, Brown \& Suter, 2010). The survey was conducted in June 2016. The final sample participants responded to the study in keeping with their most recent m-phone payment experience (within the past 12 months). The researcher 
was involved personally in identifying participants for inclusion in this study, with assistance from one trained fieldworker. After editing and cleaning the data using SPSS-data sort cases, only 474 questionnaires could be subjected to eventual data analysis. To prevent inaccuracies in determination of population estimates, a linear extrapolation technique was applied. Armstrong and Overton (1977) suggest that participants' responses be estimated beyond the original observation range by the comparing lower quartile (Q1) and upper quartile (Q4) responses. Fittingly, only insignificant differences $(p>0.05)$ of the confidence interval along gender, age group, highest academic qualification, access to m-phone paying as well as the preferred method for making payments, were reported. This result indirectly points to minimalistic levels of non-response bias in this study.

\section{Data analysis}

Initially, frequencies and exploratory factor analysis were run on SPSS (Version 23.0). Thereafter, the research hypotheses were modelled using SMART-partial least squares (SMART PLS 3). The results are presented in the same order of extraction.

Sample characteristics: Table 1 reports on the sample characteristics and the m-phone payment information.

Table 1: Sample demographic characteristics and m-phone usage information

\begin{tabular}{|c|c|c|c|}
\hline Variable & & Frequency & Percentage (\%) \\
\hline \multirow[t]{2}{*}{ Gender } & Male & 291 & $61.4 \%$ \\
\hline & Female & 183 & $38.6 \%$ \\
\hline \multirow[t]{4}{*}{ Age } & $18 \leq$ age in years $\leq 30$ & 138 & $29.1 \%$ \\
\hline & $31 \leq$ age in years $\leq 40$ & 253 & $53.4 \%$ \\
\hline & $41 \leq$ age in years $\leq 50$ & 71 & $15.0 \%$ \\
\hline & $>50$ years & 12 & $2.5 \%$ \\
\hline \multirow[t]{4}{*}{ Highest academic qualification } & Senior certificate/Matric & 195 & $41.1 \%$ \\
\hline & Diploma & 192 & $40.4 \%$ \\
\hline & Degree & 73 & $15.5 \%$ \\
\hline & Postgraduate & 14 & $3 \%$ \\
\hline \multirow[t]{4}{*}{ Monthly income (after tax) } & Less than R5000 & 73 & $15.5 \%$ \\
\hline & Between R5001 and R10000 & 95 & $20 \%$ \\
\hline & Between R10001 and R20000 & 230 & $48.5 \%$ \\
\hline & Above R20000 & 76 & $16 \%$ \\
\hline \multirow[t]{3}{*}{ General preference for payments } & Banking hall & 16 & $3.4 \%$ \\
\hline & Credit/debit card & 245 & $51.6 \%$ \\
\hline & Mobile device & 213 & $45 \%$ \\
\hline \multirow[t]{2}{*}{ Access to m-phone } & Pre-paid & 446 & $94 \%$ \\
\hline & Post-paid (contract) & 28 & $6 \%$ \\
\hline \multirow[t]{3}{*}{ Experience with m-phone paying } & $<1$ year & 14 & $3 \%$ \\
\hline & $1 \leq$ experience in years $\leq 3$ & 20 & $4.2 \%$ \\
\hline & $>3$ years experience & 440 & $92.8 \%$ \\
\hline
\end{tabular}

Table 1 discloses that the majority of participants were male (61\%) whilst 39 percent were female. The median age was reported at 39 years. Moreover, the modal qualification mix among the participants was in the order of senior certificate (41 percent) and university diploma (40 percent), with consumers reporting higher purchasing power, earning an average of between R10 001 and R20 000 per month. Regarding mobile telephony subscription, 94 percent of the sample are pre-paid customers while the vast majority of the sample members (93 percent) alluded to the fact that they have long-term access towards paying for services with their mobile phones, spanning over three years' experience. This finding is consistent with the sample's preference for making payments through credit and debit cards ( 52 percent) as well as paying for bills using mobile devices ( 45 percent). By inference, the sample profile reveals a cohort of individuals who are ready for the use of contemporary transmission channels currently available for payments. On the other hand, the sample description permits the inference that this group of users is familiar with credit and debit cards, 
which have more mature process performances, thereby implying that the sample comprises individuals that are prepared for the use of various technological innovations.

Exploratory factor analysis (EFA): Principal components analysis was applied, while the factor model was rotated in an orthogonal basis rotation by aligning the scale items with those co-ordinates through Kaiser normalisation. The criterion followed for the extraction of the factors was to have an eigen value higher than one. Moreover, it was deemed imperative that factorial loadings be higher than 0.70 , with a significant total explained variance greater than 60 percent (Malhotra, 2010). The aim of this procedure was to reduce the data set to a solution made up of a few items, thereby presenting a workable solution for eventual SEM analysis. The results showed the load of items on five factors extracted based on Eigen values $(\geq 1.0)$ and accounting for 62.8 percent cumulative variance. The extracted factors were labelled security, usefulness, ease of use, attitude and future intentions, respectively.

Upon applying the thresholds by Hair, Black, Babin and Anderson (2011) in terms of eliminating items with low communality values $(<0.50)$ and unacceptable factor loadings $(<0.70)$, most observed variables aligned as anticipated along the respective scales. Nevertheless, four items (SEC4, SEC5, EOU4 and FI5) were identified as candidates for deletion since they failed to meet the requisite criteria. In addition, the four items did not meet the cut-off criteria of 0.30 along the corrected item-to-total correlation values (Field, 2009; Pallant, 2010), but rather item statistical results (Appendix A) pointed out that the Cronbach's alpha coefficient values for the respective factors would increase after item deletion. Consequently, an expert-panel review pointed out that deletion of the four items was in order, as it would not have a deleterious effect on the original constructs' conceptualisation.

Preliminary statistics: The computed descriptive statistics are reported in Table 2.Higher mean values (mean $\geq 4.0$ ) signify sample agreeableness while standard deviation values close to 1.00 are preferred as they are well projected around the arithmetic mean. The future intentions scale had the highest mean value (mean=5.543; $\mathrm{SD}=0.938)$, followed by the attitude towards $\mathrm{m}$-phone paying scale (mean=5.505; $\mathrm{SD}=1.028)$. Relatedly, the perceived usefulness (mean=5.239; $\mathrm{SD}=0.984$ ), perceived ease of use (mean=5.131; $\mathrm{SD}=1.194$ ) and perceived security (mean=4.728; $\mathrm{SD}=1.046)$ sub-scales reported acceptable mean values.

Table 2: Descriptive statistical analysis results

\begin{tabular}{|c|c|c|c|c|c|c|}
\hline Variable & Items & $\mathbf{N}$ & Mean & $\begin{array}{r}\text { Standard } \\
\text { deviation }\end{array}$ & Skewness & Kurtosis \\
\hline Perceived security & $\begin{array}{l}\text { SEC1- } \\
\text { SEC3 }\end{array}$ & 474 & 4.728 & 1.046 & -1.096 & 1.427 \\
\hline Perceived usefulness & PU1-PU3 & 474 & 5.239 & 0.984 & -0.840 & 1.539 \\
\hline Perceived ease of use & $\begin{array}{l}\text { EOU1- } \\
\text { EOU3 }\end{array}$ & 474 & 5.131 & 1.194 & -1.379 & 1.640 \\
\hline $\begin{array}{l}\text { Attitude towards M-phone } \\
\text { paying }\end{array}$ & $\begin{array}{l}\text { ATT1- } \\
\text { ATT4 }\end{array}$ & 474 & 5.505 & 1.028 & -0.955 & 1.554 \\
\hline $\begin{array}{l}\text { Future intentions towards M- } \\
\text { phone paying }\end{array}$ & FI1-FI4 & 474 & 5.543 & 0.938 & -0.977 & 1.385 \\
\hline
\end{tabular}

Table 2 reveals that perceived ease of use had the highest standard deviation value reported at 1.194 indicating a greater dispersion with regard to the distance of interpretations from the measurement of the arithmetic mean, for that variable.Measures of dispersion were calculated using the skewness (ranging between -0.840 and -1.379) and kurtosis statistics (ranging between 1.385 and 1.640). While data normality is not a compulsory pre-cursor in SMART PLS 3 analysis, none of the values fell outside the \pm 2 range, thereby suggesting that the data were relatively flat (Malhotra, 2010).

Evaluation of the measurement (outer) model: PLS modelling was performed to fulfil the dual obligation of first, creating valid model specifications and secondly, fitting the model already specified. PLS modelling 
requires standardised latent variable scores, since the latter are linear combinations of the indicator variables. Therefore, the first step in applying the PLS-SEM algorithm was to normalise the indicator variables to have a mean of zero and a standard deviation of one. As a result, the standardised model yielded factor loadings and path coefficients ranging between zero and \pm 1 on the outer and inner models, respectively, with values nearer to one denoting power. The m-phone payments measurement model was constructed from five constructs renamed as follows: security (perceived security), usefulness (perceived usefulness), ease of use (perceived ease of use), attitude (attitude towards m-phone paying) and future intentions (future intentions towards m-phone paying). Table 3 reports on the measurement model results.Upon analysing the measurement model estimates, the following thresholds were considered:

- Standardised factor loadings greater than 1.0 or below -1.0

- Low factor loadings (below 0.70)

- Insignificant factor loadings

Table 3: Measurement (outer) model results

\begin{tabular}{|c|c|c|c|c|}
\hline Construct & $\begin{array}{l}\text { Item } \\
\text { identifier }\end{array}$ & Summary & $\begin{array}{l}\text { Factor } \\
\text { loading }\end{array}$ & $\begin{array}{l}\text { VIF (outer) } \\
\text { values }\end{array}$ \\
\hline \multirow[t]{3}{*}{ Security } & SEC1 & $\begin{array}{llll}\text { Requests my } & \text { approval } & \text { before } & \text { processing } \\
\text { transactions } & & & \\
\end{array}$ & 0.774 & 1.524 \\
\hline & SEC2 & $\begin{array}{l}\text { Does not abuse billing information during } \\
\text { transaction }\end{array}$ & 0.843 & 1.570 \\
\hline & SEC3 & I have confidence in the security of transactions & 0.828 & 1.329 \\
\hline \multirow[t]{3}{*}{ Usefulness } & PU1 & $\begin{array}{l}\text { Helps me make payments I usually make within a } \\
\text { banking hall }\end{array}$ & 0.838 & 1.128 \\
\hline & PU2 & Helps me increase the effectiveness of payments & 0.781 & 1.436 \\
\hline & PU3 & $\begin{array}{l}\text { Using the m-phone to make payments helps me } \\
\text { increase my productivity }\end{array}$ & 0.857 & 1.238 \\
\hline \multirow[t]{2}{*}{ Ease of use } & $\begin{array}{l}\text { EOU1 } \\
\text { EOU2 }\end{array}$ & $\begin{array}{l}\text { Mental effort is not required to complete the } \\
\text { payment } \\
\text { It is easy to do what I want to do }\end{array}$ & 0.779 & 1.450 \\
\hline & EOU3 & M-phone paying is an easy-to-use tool & 0.731 & 1.926 \\
\hline \multirow[t]{2}{*}{ Attitude } & $\begin{array}{l}\text { ATT1 } \\
\text { ATT2 }\end{array}$ & $\begin{array}{l}\text { M-phone paying is a good idea to me } \\
\text { M-phone paying is wise }\end{array}$ & $\begin{array}{l}0.773 \\
0.729\end{array}$ & $\begin{array}{l}2.714 \\
2.652\end{array}$ \\
\hline & $\begin{array}{l}\text { ATT3 } \\
\text { ATT4 }\end{array}$ & M-phone paying is pleasant to me & 0.754 & 2.051 \\
\hline \multirow{4}{*}{$\begin{array}{l}\text { Future } \\
\text { intentions }\end{array}$} & FI1 & I plan to make payments using my mobile phone & 0807 & 1411 \\
\hline & FI2 & $\begin{array}{l}\text { I foresee myself making payments using my mobile } \\
\text { phone in the short-term }\end{array}$ & 0.810 & 1.348 \\
\hline & FI3 & $\begin{array}{l}\text { I am very likely to make payments using my mobile } \\
\text { phone in the long-term }\end{array}$ & 0.817 & 1.208 \\
\hline & FI4 & $\begin{array}{l}\text { I will encourage my friends and relatives to make } \\
\text { payments using their mobile phones }\end{array}$ & 0.777 & 1.321 \\
\hline \multicolumn{3}{|c|}{ Recommended thresholds } & $\geq 0.70$ & $<5.0$ \\
\hline
\end{tabular}

To the exclusion of indicator variable ATT4, Table 3 reveals acceptable estimates on the outer model, with all significant and greater than 0.70 factor loadings, which is considered ideal by Malhotra (2010). Nevertheless, while ATT4 reported a factor loading of 0.618 (close to 0.70), an expert-panel review pointed out that deletion of the item would alter the original construct's conceptualisation andfor that extrapolation, the indicator variable was retained in this study. The SMART PLS 3 report revealed an RMS theta value of 0.093, which indicates model fit, whereas values higher than 0.12 could suggest a lack thereof (Henseler, Ringle \& 
Sarstedt, 2015). The RMS theta assesses the degree to which the outer model residuals actually correlate (Lohmoller, 1989). It is advisable that the measure is close to zero to imply minor correlations.

Multicollinearity assessment of the outer model: Upon following standard procedures in marketing research, the variance inflation factor (VIF) values $\left(\mathrm{VIF}_{\mathrm{xs}}=1 / \mathrm{TOL}_{\mathrm{xs}}\right)$ were computed in lieu of reporting the collinearity issues in this work. Generally, VIF values should not exceed 5.0 while tolerance values below 0.20 are a cause of concern. An alternative method to evaluate collinearity concerns is by computing a bivariate matrix with correlation coefficients greater than $0.60(r>0.60)$ signalling collinearity issues in PLS path models (Hair et al. 2011).The SMART PLS 3 output reports the following: VIF (outer) values for security (1.329 to 1.570), usefulness (1.128 to 1.436), ease of use (1.450 to 1.926), attitude (2.009 to 2.714) and future intentions (1.208 to 1.411). In addition, the highest correlation coefficient value in the correlation matrix was reported at $r=0.591$ (refer to Table 5), which is considered acceptable. As a result, the three computed statistics signal that there were no multicollinearity problems within the dataset.

Reliability assessment: In this study, it was considered imperative to determine whether the measures used confer strength of the study. In this vein, the internal consistency reliability among the sub-scales as well as the validity measures for this research is reported on in Table 4.

Table 4: Reliability and validity results

\begin{tabular}{|c|c|c|c|c|c|c|}
\hline \multirow[b]{2}{*}{ Construct } & \multicolumn{3}{|c|}{ Reliability statistics } & \multicolumn{3}{|c|}{ Validity statistics } \\
\hline & $\operatorname{Alpha}(\alpha)$ & Rho_A & CR & AVE & SV & Root of AVE \\
\hline Security & 0.884 & 0.905 & 0.911 & 0.631 & 0.319 & 0.794 \\
\hline Usefulness & 0.881 & 0.982 & 0.911 & 0.673 & 0.198 & 0.820 \\
\hline Ease of use & 0.872 & 0.922 & 0.905 & 0.656 & 0.284 & 0.811 \\
\hline Attitude & 0.943 & 0.943 & 0.957 & 0.815 & 0.431 & 0.903 \\
\hline $\begin{array}{l}\text { Future } \\
\text { intentions }\end{array}$ & 0.933 & 0.935 & 0.946 & 0.715 & 0.376 & 0.845 \\
\hline $\begin{array}{l}\text { Recommended } \\
\text { thresholds }\end{array}$ & $\geq 0.70$ & $\geq 0.70$ & $\geq 0.70$ & $\geq 0.50$ & $\begin{array}{l}\leq \text { AVE } \\
\text { values }\end{array}$ & $\begin{array}{l}\text { > highest } \\
\text { correlation } \\
\text { coefficient }(r)\end{array}$ \\
\hline
\end{tabular}

While only one statistical measure is necessary for reliability assessment, it is not always sufficient, especially where multivariate statistical procedures are applied. Therefore, unidimensionality was assessed by checking, Cronbach's alpha coefficient, Dillon-Goldstein's rho values as well asprincipal component analysis of each construct's composite reliability (CR). While Chin (1998) and Höck and Ringle (2010) recommend predeterminable thresholds of 0.70 or greater, this study reported values above 0.80 across all three statistics, which is considered good reliability for confirmatory research (Henseler et al., 2015). Of note, Cronbach's alpha values for the individual sub-scales ranged from 0.872 to 0.943 . Dillon-Goldstein's rho values ranged between 0.905 and 0.982 , whereas CR values ranged between 0.905 and 0.957 . 
Table 5: Correlation analysis

\begin{tabular}{|c|c|c|c|c|c|}
\hline Construct & 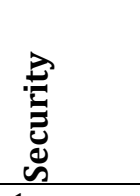 & 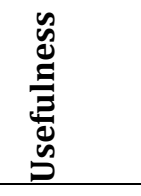 & 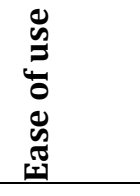 & 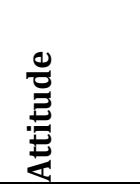 & \\
\hline Security & 1 & & & & \\
\hline Usefulness & $0.406^{* *}$ & 1 & & & \\
\hline Ease of use & $0.400^{* *}$ & $0.399^{* *}$ & 1 & & \\
\hline Attitude & $0.353^{* *}$ & $0.254^{* *}$ & $0.230^{* *}$ & 1 & \\
\hline Future intentions & $0.282^{* *}$ & $0.273^{* *}$ & $0.177^{* *}$ & $0.591^{* *}$ & 1 \\
\hline \multicolumn{6}{|c|}{${ }^{* *} p=0.01$ level $(2$-tailed $)$} \\
\hline Square roots of $A V E$ & 0.794 & 0.820 & 0.811 & 0.903 & 0.845 \\
\hline
\end{tabular}

Validity assessment: Construct validity of this research was ascertainedusing a tripartite set of evaluative measures. Initially, convergent validity of the study was determined by computing AVE values. AVE is the average of communalities for each latent factor in a reflective model. In general, the AVE values should be at least 0.50, which means that the construct explains at least half of the variance of its observed variables (Malhotra, 2010). AVE values below 0.50 indicate error variance levels that surpass the explained variance (Chin, 1998). The AVE values reported in this study were within the acceptable range $(0.631 \leq A V E \leq 0.815)$, implying that more of the variance along each indicator variable was shared with its respective construct. Moreover, the factor loadings for the indicators that were incorporated in the outer model exceeded the 0.70 cut-off point (refer to Table 3), thereby signalling convergent validity of the outer model.In terms of discriminant validity, Fornell and Larcker's (1981) criterion, shared variance values as well as the Heterotrait-monotrait ratio of correlations (HTMT) were employed as shown on Table 5.

Fornell and Larcker's (1981) criterion dictates that the observed square root of AVE values should be larger than the highest computed value in the correlation matrix, if the constructs are to bear theoretical and practical uniqueness. Table 5 shows that all correlation values are positive and significant at the 0.01 level, with the highest coefficient value reported between attitude and intentions $(r=0.591 ; p=0.01)$. This value is subordinate to the computed square root of the AVE values (between 0.794 and 0.903 ). Relatedly, the shared variance values ranged between 0.198 and 0.431 across all constructs (Refer to table 4), which is subordinate to the value of all AVE estimates computed in this study. Nevertheless, Henseleret al. (2015) showed by means of a simulation study, that applying Fornell and Larcker's (1981) criterion alone, was not an adequate measure of discriminant validity. The authors, therefore, advised the use of the HTMT ratio as an alternative approach. The HTMT ratio values reported in Appendix B fell between 0.195 and 0.734 across all pairs of constructs, which is below 0.90 , thereby providing robust evidence of discriminant validity in this study.

Evaluation of the inner model: An examination of the $t$-values, coupled with the direction and weight of the path regression coefficients, enabled the researcher to establish which hypotheses were supported by the data. Initially, a goodness of fit (GoF) index was computed manually, since GoF is not output by SmartPLS. The following formula was applied:

$\mathrm{GoF}=\sqrt{ } \mathrm{AVE} * \mathrm{R}^{2}$

While GoF values vary from 0 to 1 , higher values reflect better explanation (Henseler \& Sarstedt, 2013). The calculated GoF value in this work is 0.54 , implying a valid inner model since this calculated value exceeds the threshold of GoF $>0.36$ suggested for large effect sizes $\left(R^{2} \geq 0.26\right)$ (Wetzels, Odekerken-Schröder \& van Oppen, 2009). In addition, NFI was reported at 0.903 whereas SRMR was reported at 0.073 which is considered good model fit (Hu \& Bentler, 1999).In this study, factor scores for the inner weights were estimated based on the Path weighting factor scheme. The results presented in Figure 1 show that all the hypothesised relationships were supported. 


\section{Figure 1: Measurement and structural model results}

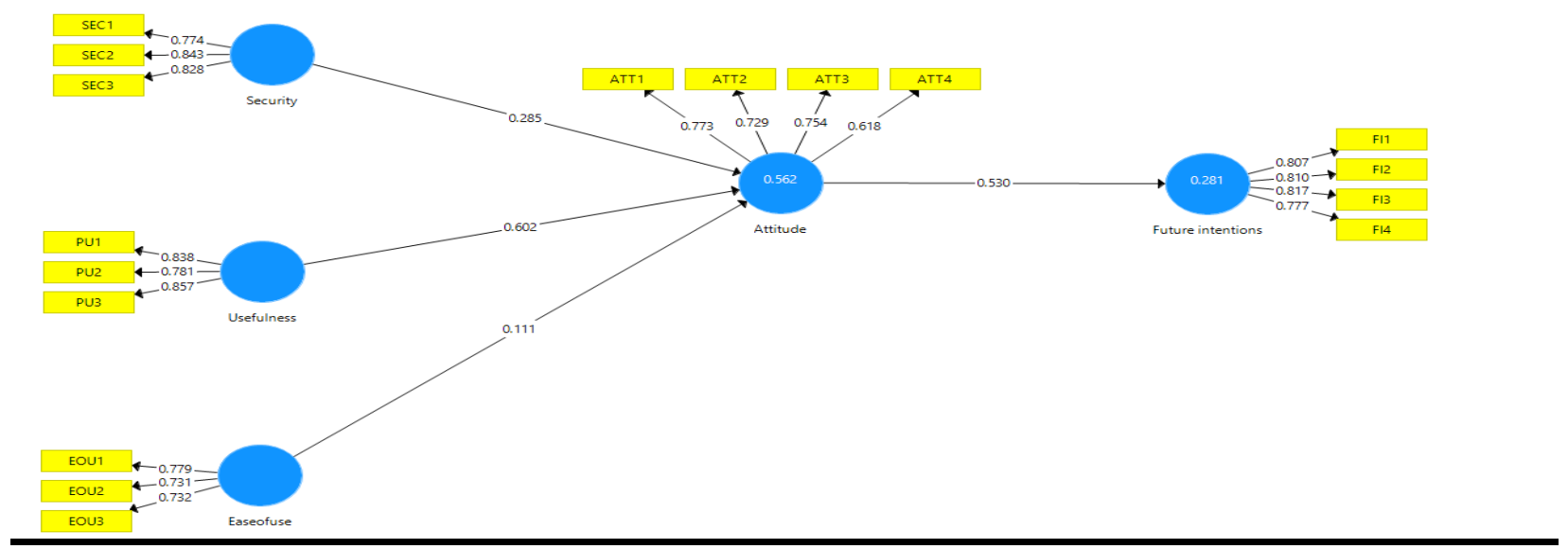

Shortened terminology for SEM analysis:

Usefulness = Perceived usefulness; Ease of use $=$ Perceived ease of use; Security = Perceived security; Attitude= Attitude towards m-phone payments; Future intentions = Future intentions towards m-phone payments.

The results provide support for the four proposed relationships along the specified paths. The results shown on Figure 1 indicate that the research model explains 56.2 percent $\left(R^{2}=0.562\right)$ and 28.1 percent $\left.R^{2}=0.281\right)$ of the differences in attitude and future intentions, which Chin (1998:323) describes to be both strong and moderate explanatory power, respectively.

Table 6: Inner model estimates

\begin{tabular}{lcllll}
\hline Causal path & Hypothesis & $\begin{array}{l}\text { Path } \\
\text { coefficient } \\
\text { estimate }\end{array}$ & $\begin{array}{l}\boldsymbol{t} \text { - } \\
\text { Statistic }\end{array}$ & VIF (inner) & Result \\
\hline Security $\longleftarrow$ attitude & $\mathrm{H}_{\mathrm{a}} 1(+)$ & 0.285 & 2.767 & 1.303 & Supported \\
Usefulness $\longleftarrow$ attitude & $\mathrm{H}_{\mathrm{a}} 2(+)$ & 0.602 & 12.769 & 1.301 & Supported \\
Ease of use $\leftarrow$ attitude & $\mathrm{H}_{\mathrm{a}} 3(+)$ & 0.111 & 2.038 & 1.194 & Supported \\
Attitude $\leftarrow$ Future & $\mathrm{H}_{\mathrm{a}} 4(+)$ & 0.530 & 9.991 & 1.009 & Supported \\
\hline intention & & & & & \\
\hline
\end{tabular}

Table 6 reveals that the tolerance statistic values for the inner model ranged between 2.038 and 12.769 (greater than +1.96), indicating that the four specified paths were significant. Moreover, the computed VIF values were all below 5.0 (ranging between 1.009 and 1.303), thereby signifying absence of collinearity problems in the model.

Discussion: Figure 1 indicates that perceived security (Path estimate $=+0.285 ; p=0.000$ ) has a significant positive influence on consumers' attitude towards m-phone paying. Consistent with the first hypotheses, a direct and significant effect was established between the two constructs. As a result, $\mathrm{H}_{1}$ is supported in this study. This hypothesised relationship is consistent with the finding of Meharia (2012) as well as Wang and Idertsog's (2015) research on m-payments. In addition, the studies by McKechnieet al. (2006) as well as Wang, Wang, Lin and Tang (2003) supported the direct impacts of security on attitude towards online retail financial services and Internet banking, respectively. Inevitably, the underlying customer beliefs about safety and risks take paramount consideration upon shaping consumers' attitude towards making payments through the mobile phone. From the findings, it is apparent that South African consumers who conduct payments using mobile phones are particularly concerned about security issues and are prepared to place the 
responsibility of security solely on the service provider. The moderate coefficient result along this path suggests that security is an important consideration among South African consumers intending to make payments along mobile devices. The absence of authorisation requests and encryption software, such as Thawte, Verisign or TPO seals, reflects sufficient evidence of how consumers' details may be manipulated when conducting transactions using their mobile devices.

In terms of the second hypotheses, the inner model results indicate that perceived usefulness (Path estimate $=+0.602 ; p=0.000$ ) had the strongest, direct influence on attitude. As such, $\mathrm{H}_{2}$ is supported owing to the statistically significant result. Liébana-Cabanillas et al. (2014) who confirm the influence of usefulness on consumers' attitude towards m-phone paying also established a direct effect. Relatedly, previous studies show that usefulness determines consumers' attitude towards a new payment system more strongly among experienced users (Erasmus et al., 2015) because they already know how this type of payment system works in terms of functionalities and risks. Put simply, usefulness implies that a customer will conduct m-phone payments based on the degree to which it is believed to assist in processing daily tasks, better. The inference in this hypothesis is that when consumers find m-phone services to be valuable and beneficial for their everyday payment requirements, they are likely to develop positive cognitive and affective evaluations towards the payment solution.

The results of the structural model indicate that perceived ease of use does have a significant and direct effect on consumers' attitude towards m-phone paying (Path estimate $=+0.111 ; p=0.000$ ). As a result, $\mathrm{H}_{3}$ is supported, implying that perceived difficulty associated with transacting on mobile devices has a significant bearing on the attitudinal evaluations by existing m-phone users. The fourth hypotheses were aimed at testing whether attitude influences the future intentions of consumers towards $m$-phone paying. The results of the inner model indicate a significant direct influence (Path estimate $=+0.530 ; p=0.000$ ) and shows that there is a significant effect. As a result, $\mathrm{H}_{4}$ is supported in this study. Although this finding strongly supports the proposed model, researchers could still develop further inquiry into this path across different contexts as inconsistent results have been established in the past with attitude having been extensively used as a predictor of future intentions in previous works. A case in point is the research by Erasmus et al. (2015) who found an insignificant influence of attitude on behavioural intentions in their study of enterprise resource systems across a B2B context.

\section{Conclusion}

In practice, this paper provides information to the business sectors involved to assess the response of the market towards an existing service and allows them to build respective strategies of segmentation and communication, from an understanding of the factors that precede intention towards continued usage of $\mathrm{m}$ phone payment services. As an imperative, it is noteworthy that the model of commercial payments in South Africa is intricate, owing to an existing regulatory environment that is defined by rigid macro-policy makers. To further compound this problem, there exist fragmented technological solutions with the participation of different sectors of the economy. In this eco-system, different and somewhat competing players co-exist, including banks, acquisition companies, commercial establishments, electronic transaction processing companies, telecom providers, retailers, consumers and support service providers. As such, the future growth and development of m-phone payment services depends on an understanding of market characteristics coupled with the preparation of the internal capacity of entities interested in this business. The fact that there are more mobile devices than individuals enables telecom carriers to dream of fulfilling the requirements of money transfer and payments for general users, particularly the self-employed and people without access to a bank account, either through their post or prepaid plans. On the other end, all players involved in the process of paying can gain from the offer of this new service.

Limitations and future research avenues: The results of this study should be interpreted in light of the study's shortcomings. One limitation is that its population frame poses implications for sampling bias. In this study, a group of m-phone payment users was nominatedbased on a referral basis, which could affect the representativeness of the findings and the subsequently derived conclusions. Therefore, prospective research endeavours could attempt to enlarge the scope of this work by utilising probability based methods of drawing samples. Besides, this research only studied one mobile payment system, while there are currently other 
technologies such as the NFC payment systems (Near Field Communication) based on proximity technology or the QR codes and even recent ones such as biometric fingerprints or voice payment methods. A comparison study of all available instruments would allow researchers to acquire external validity in the results presented and thereby, establish a generalisation of consumers' behaviour towards the new mobile payment systems. In addition, the study can be complemented with the evaluation of the impact of the factors prior to adoption of mobile payments such as performance and effort expectations, social influence, perceived cost and risk, while including the effect of moderating variables, such asage, gender, experience and willingness to use, as proposed by Venkatesh and Morris (2000).

Acknowledgements: The author of this work wishes to thank the trained fieldworker (Postgraduate student) who assisted with the data collection process.

\section{References}

Abrahão, S. R., Moriguchi, S. N. \& Andrade, D. F. (2016). Intention of adoption of mobile payment: an analysis in the light of the unified theory of acceptance and use of technology (UTAUT). RAI Revistade AdministraçãoeInovação, 13, 221-230.

Accenture. (2014). Driving the adoption of mobile payments-what SA consumers want. [Online] Available at: $\mathrm{http} / / \quad$ www.cas-ag.eu/SiteCollectionDocuments/Local_South_Africa/pdf/Accenture-DrivingAdoption-for-Mobile-Payments-What-do-consumers-South-Africa-want.pdf. Accessed 18/08/2014.

Ajzen, I. (1989). Attitude Structure and Behaviour. In Pratkanis, A.R., Beckler, S.J. \& Greenwald A.G. (Eds.), Attitude Structure and Function (pp. 241-274),Hillsdale, NJ: Erlbaum.

Armstrong, J. S. \& Overton, T. S. (1977). Estimating non-response bias in mail surveys. Journal of Marketing Research, 14(3), 396-402.

Cernev, A. K. (2010). Mobile banking in Brazil: critical events, trajectory and expected scenarios. PhD thesis, Sao Paulo: Getulio Vargas Foundation. 378 p. [Online] Available at: http://bibliotecadigital.fgv.br/dspace/handle/10438/ 8167. Accessed 16/02/2016.

Chin, W. W. (1998). Issues and opinion on structural equation modelling. Management Information Systems Quarterly, 22(1), 7-16.

Choi, J., Lee, A. \& Ok, C. (2014). The effects of consumer perceived risk and benefit on attitude and behavioural intention: a study of street food. Journal of Travel and Tourism, 30(1), 222-237.

Churchill, G. A., Brown, T. J. \&Suter, T. A. (2010). Basic marketing research, $\left(7^{\text {th }}\right.$ ed), Canada: South Western, Cengage Learning.

Dahlberg, T., Mallat, N., Ondrus, J. \& Zmijewska, A. (2008). Past, present and future of mobile payments research: a literature review. Journal ofElectronic Commerce Research and Applications, 7(2), 165181.

Davis, F. D., Bagozzi, R. P. \&Warshaw, P. R. (1989). User acceptance of computer technology: comparisons of two theoretical models. Journal of Management Science, 35(8), 982-1003.

Diniz, E. H., Cernev, A. K. \& Albuquerque, J. P. D. (2011). Mobile money and payment: a literature review based on academic and practitioner-oriented publications (2001-2011). In Proceedings of the 4th Annual Workshop ICT in Global Development - Workshop of the International Conference on Information Systems ICIS 2011, Shangai (pp. 1-35).

Dlodlo, N. (2015). The use of m-payment services in South Africa: a value based perception approach. International Business and Economics Research Journal, 14(1), 159-178.

Donner, J. \& Tellez, C. A. (2008). Mobile banking and economic development: linking adoption, impact and use. Asian Journal of Communication, 18(4), 318-322.

Duane, A., O'Reilly, P. \& Andreev, P. (2014). Realising m-payments: modelling consumers' willingness to mpay using smart phones. Behaviour and Information Technology, 33(4), 318-334.

Erasmus, E., Rothmann, S. \& Van Eeden, C. (2015). A structural model of technology acceptance. South African Journal of Industrial Psychology, 41(1), 1-12.

Field, A. (2009). Discovering Statistics Using SPSS, (3rd ed.), London: Sage.

Fishbein, M. \&Ajzen, I. (1975). Belief, Attitude, Intention and Behaviour: an Introduction to Theory and Research, Reading, MA: Addison-Wesley.

Fishbein, M. (1963). An investigation of the relationships between beliefs about an object and the attitude toward that object. Human Relations, 16(3), 233-240. 
Fornell, C. \& Larcker, D. F. (1981). Evaluating structural equation models with unobservable variables and measurement error. Journal of Marketing Research, 18(1), 39-50.

Gartner Group. (2012). Forecast: Mobile payment, worldwide, 2009-2016, [Online] Available at: http://www.gartner.com/resId11/42010515. Accessed 15/05/2016.

Ghezzi, A., Renga, F., Balocco, R. \&Pescetto, P. (2010). Mobile payment applications: offer state of the art in the Italian market. Information, 12(5), 3-22.

Grubb, L. (2012). How ready is Africa for mobile payments? [Online] Available at: http://www.technologybanker.com/news-analysis/how-ready-is-africa-for-mobilepayments.U8kyuvmSw1y. Accessed 18/07/ 2016.

Hair, J. F., Ringle, C. M. \& Sarstedt, M. (2011). PLS-SEM: indeed a silver bullet. Journal of Marketing Theory and Practice, 18(2), 139-152.

Henseler, J., Ringle, C. M. \& Sarstedt, M. (2015). A new criterion for assessing discriminant validity in variancebased structural equation modelling. Journal of the Academy of Marketing Science, 43(1), 115-135.

Höck, M. \& Ringle, C. M. (2010). Local strategic networks in the software industry: An empirical analysis of the value continuum. International Journal of Knowledge and Management Studies, 4(1), 132-151.

Howard, J. \& Sheth, J. (1969). Thetheoryofbuyerbehaviour, New York: John Wiley.

Hsiao, W. H. \& Chang, T. S. (2013). Understanding consumers' continuance intention towards mobile advertising: a theoretical framework and empirical study. Journal of Behavioural Information technology, 33(7), 730-742.

Jeong, B. \& Yoon, T. E. (2013). An empirical investigation on consumer acceptance of mobile banking services. Journal of Business Management Research, 2(1), 31-40.

Kim, Y. J., Chun, J., U. \& Song, J. (2009). Investigating the role of attitude in technology acceptance from an attitude strength perspective. International Journal of Information Management, 29, 67-77.

Kim, C., Mirusmonov, M. \& Lee, I. (2010). An empirical examination of factors influencing the intention to use mobile payment. Computers in Human Behaviour, 26(3), 310-322.

Leong, L. Y., Hew, T. S., Tan, G. W. H. \& Ooi, K. B. (2013). Predicting the determinants of the NFC-enabled mobile credit card acceptance: a neural networks approach. Expert Systems with Applications, 40(2013), 5604-5620.

Liébana-Cabanillas, F., Sanchez-Fernandez, J. \& Munoz-Leiva, F. (2014). Role of gender on acceptance of mobile payment. Journal of Industrial Management and Data Systems, 114(2), 220-240.

Lin, H. F. (2011). An empirical investigation of mobile banking adoption: The effect of innovation attributes and knowledge-based trust. InternationalJournal of Information Management, 31(1), 252-260.

Liu, J., Kauffman, R. J. \& Ma, D. (2015). Competition, cooperation, and regulation: understanding the evolution of the mobile payments technology ecosystem. Journal ofElectronic Commerce Research and Applications, 14(5), 372-391.

Lohmöller, J. B. (1989). Latent Variable Path Modeling With Partial Least Squares, Heidelberg: Physica-Verlag.

Malhotra, N. K. (2010). Marketing research: an applied orientation, (6th ed.), New Jersey: Prentice- Hall.

Malhotra, N. K. \& Mccort, J. D. (2001). A cross-cultural comparison of behavioural intentions models. International Marketing Review, 18(3), 235-269.

Mallat, N. (2007). Exploring consumer adoption of mobile payments: a qualitative study. The Journal of Strategic Information Systems, 16(4), 413-432.

McKechnie, S., Winklhofer, H. \& Ennew, C. (2006). Applying the technology acceptance model to the online retailing of financial services. International Journal of Retail and Distribution Management, 34(4/5), 388-410.

Meharia, P. (2012). Assurance on the reliability of mobile payment system and its effects on it's' use: an empirical examination. Journal of Accounting and Management Information System, 11(1), 97-111.

Miltgen, C. L., Popovic, A. \& Oliveira, T. (2013). Determinants of end-user acceptance of biometrics: integrating the Big 3 of technology acceptance with privacy context. Decision Support Systems, 56, 103-114.

Oliveira, T., Thomas, M., Baptista, G. \& Campos, F. (2016). Mobile payment: understanding the determinants of customer adoption and intention to recommend the technology. Computers in Human Behaviour, 61(2016), 404-414.

Ondrus, J. \& Pigneur, Y. (2007). Towards a holistic analysis of mobile payments: a multiple perspective approach. Journal ofElectronic Commerce Research and Applications, 5(3), 246-257. 
O'Reilly, P., Duane, A. \& Andreev, P. (2012). To m-pay or not to m-pay? Realising the potential of smart phones: conceptual modeling and empirical validation. Electronic Markets, 22(4), 229-241.

Overbr. (2014). MídiaCorporativa. São Paulo: Î́ndice Global de PagamentosMóve is. [Online] Available at: http://overbr.com.br/midia-corporativa/indice-global-de-pagamentos-move. Accessed 5/01/2017.

Pallant, J. (2010). SPSS Survival Manual: a Step-By-Step Guide to Data Analysis Using SPSS for Windows, Buckingham: Open University Press.

Pham, T. T. T. \& Ho, J. C. (2015). The effects of product-related, personal-related factors and attractiveness of alternatives on consumer adoption of NFC-based mobile payments. Technology in Society, 43(2015), 159-172.

Rao, S. \& Troshani, I. A. (2007). Conceptual framework and propositions for the acceptance of mobile services. Journal of Theoretical and Applied Electronic Commerce Research, 2(2), 61-73.

Revels, J., Tojib, D. \& Tsarenko, Y. (2010). Understanding consumer intention to use mobile services. Journal of Australasian Marketing, 18, 74-80.

Schierz, P. G., Schilke, O. \&Wirtz, B. W. (2010). Understanding consumer acceptance of mobile payment services. Journal of Electronic Commerce Research and Applications, 9(1), 209-216.

Schiffman, L. G. Kanuk, L. L. \&Wisenblit, J. (2010). Consumer behaviour, (10th ed.), New Jersey: Prentice-Hall.

Slade, E., Williams, M., Dwivedi, Y. \& Piercy, N. (2014). Exploring consumer adoption of proximity mobile payments. Journal of Strategic Marketing, 23(3), 1-15.

Solomon, M., Bamossy, G., Askegaard, S. \& Hogg, M. K. (2006). Consumer Behaviour: a European Perspective, (3rd ed.), Edinburg: Prentice-Hall.

Statistica Corporation. (2015). Mobile payment transaction volume 2010-2017. The Statistics Portal. Available at: http://www.statista.com/statistics/226530/mobile-paymenttransaction-volumeforecast/. Accessed 01/09/16.

Tan, G., Ooi, K. B, Chong, S. C. \& Hew, T. S. (2014). NFC mobile credit card: the next frontier of mobile payment? Telematics and Informatics, 31(2), 292-307.

Teo, T., Luan, W. S. \& Sing, C. C. (2008). A cross-cultural examination of the intention to use technology between Singaporean and Malaysian pre-service teachers: an application of the Technology Acceptance Model (TAM). Educational Technology and Society, 11(4), 265-280.

Teo, A. C., Tan, G. W. H., Ooi, K. B., Hew, T. S. \& Yew, K. T. (2015). The effects of convenience and speed in mpayment. Industrial Management and Data Systems, 115(2), 311-331.

Venkatesh, V. \& Morris, M. G. (2000). Why don't men ever stop to ask for directions? Gender, social influence and their role in technology acceptance and usage behavior. Management Information Systems Quarterly, 24(1), 115-139.

Wang, H. M. \&Idertsog, B. (2015). A study on user's intention of using mobile payments. International Journal of Sciences: Basic and Applied Research, 24(6), 433-449.

Wang, Y. S., Wang, Y. M., Lin, H. H. \& Tang, T. I. (2003). Determinants of user acceptance of Internet banking: an empirical study. International Journal of Service Industry Management, 14(5), 501-519.

Yousafzai, S., Pallister, J. \&Foxall, G. (2009). Multi-dimensional role of trust in Internet banking adoption. Journal of the Service Industries, 29(5), 591-605.

$\mathrm{Yu}, \mathrm{C}$. S. (2012). Factors affecting individuals to adopt mobile banking: empirical evidence from the UTAUT model. Journal of Electronic Commerce Research, 13(2), 104-121.

Zhong, J. (2009). A comparison of mobile payment procedures in Finnish and Chinese markets. 22 ${ }^{\text {nd }}$ BLED econference e-enablement: facilitating an open, effective and representative e-society. 
Appendix A

KMO and Bartlett's Test

Kaiser-Meyer-Olkin Measure of Sampling Adequacy. $\quad .851$

Bartlett's Test of Sphericity Approx. Chi-Square

8785.438

\begin{tabular}{ll} 
df & 496 \\
\hline Sig. & .000 \\
\hline
\end{tabular}

Rotation sums of squared loadings

Total Variance Explained

\begin{tabular}{llll}
\hline \hline Component & Total & \% of Variance & Cumulative \% \\
\hline \hline 1 & 3.619 & 10.456 & 10.456 \\
\hline 2 & 2.936 & 11.635 & 22.091 \\
\hline 3 & 1.309 & 12.883 & 34.974 \\
\hline 4 & 1.188 & 13.599 & 48.573 \\
\hline 5 & 1.069 & 14.219 & 62.792 \\
\hline \hline
\end{tabular}

Rotated Component Matrix

\begin{tabular}{|c|c|c|c|c|c|c|}
\hline Item & Factor 1 & :tor 2 & $\cdot 3$ & ctor 4 & -Factor 5 & Communalities \\
\hline$\overline{S E C 1}$ & 0.785 & & & & & 0.793 \\
\hline SEC2 & 0.793 & & & & & 0.607 \\
\hline SEC3 & 0.704 & & & & & 0.569 \\
\hline SEC4* & 0.421 & & & & & 0.332 \\
\hline SEC5* & 0.476 & & & & & 0.426 \\
\hline PU1 & & 0.730 & & & & 0.673 \\
\hline PU2 & & 0.749 & & & & 0.629 \\
\hline PU3 & & 0.790 & & & & 0.616 \\
\hline$\overline{\text { EOU1 }}$ & & & 0.788 & & & 0.674 \\
\hline EOU2 & & & 0.753 & & & 0.592 \\
\hline EOU3 & & & 0.724 & & & 0.648 \\
\hline EOU4* & & & 0.412 & & & 0.339 \\
\hline $\begin{array}{l}\text { ATT1 } \\
\end{array}$ & & & & 0.761 & & 0.543 \\
\hline ATT2 & & & & 0.722 & & 0.620 \\
\hline ATT3 & & & & 0.774 & & 0.586 \\
\hline ATT4 & & & & 0.774 & & 0.651 \\
\hline FI1 & & & & & 0.779 & 0.541 \\
\hline$\overline{\mathrm{FI} 2}$ & & & & & 0.745 & 0.612 \\
\hline FI3 & & & & & 0.728 & 0.634 \\
\hline FI4 & & & & & 0.796 & 0.600 \\
\hline FI5* & & & & & 0.480 & 0.387 \\
\hline
\end{tabular}

Item-total statistics

\begin{tabular}{llllll}
\hline & \multicolumn{2}{l}{$\begin{array}{l}\text { Scale Mean if ItemScale Variance } \\
\text { Deleted }\end{array}$} & ifem Deleted & ifCorrected & \multicolumn{2}{c}{ Item-Squared } & \multicolumn{2}{c}{ MultipleCronbach's Alpha if } \\
& Total Correlation & Correlation & Item Deleted \\
\hline SEC1 & 113.399 & 491.737 & .702 & .687 & .651 \\
\hline
\end{tabular}


Vol. 9, No. 2, pp. 114-130, April 2017

\begin{tabular}{llllll} 
SEC2 & 113.297 & 497.587 & .646 & .569 & .652 \\
\hline SEC3 & 113.566 & 494.661 & .612 & .516 & .652 \\
\hline SEC4 & $\mathbf{1 1 3 . 3 4 8}$ & $\mathbf{4 9 7 . 1 0 6}$ &. $\mathbf{2 6 9}$ & .396 & .831 \\
\hline SEC5 & $\mathbf{1 1 3 . 3 5 0}$ & $\mathbf{4 9 8 . 2 2 4}$ & .637 & .595 & .883 \\
\hline PU1 & 113.403 & 495.451 & .635 & .602 & .659 \\
\hline PU2 & 113.271 & 497.606 & .662 & .257 & .656 \\
\hline PU3 & 113.319 & 499.145 & .629 & .542 & .652 \\
\hline EOU1 & 113.209 & 500.969 & .609 & .506 & .655 \\
\hline EOU2 & 113.240 & 498.077 & .712 & .661 & .709 \\
\hline EOU3 & 113.280 & 498.851 & .658 & .529 & .652 \\
\hline EOU4 & $\mathbf{1 1 3 . 3 0 0}$ & $\mathbf{4 9 7 . 0 0 1}$ & .288 & .316 & .881 \\
\hline ATT1 & 113.247 & 499.352 & .643 & .550 & .652 \\
\hline ATT2 & 113.267 & 497.066 & .722 & .628 & .651 \\
\hline ATT3 & 113.140 & 498.568 & .652 & .602 & .699 \\
\hline ATT4 & 113.380 & 498.341 & .741 & .257 & .645 \\
\hline FI1 & 113.200 & 497.234 & .736 & .542 & .659 \\
\hline FI2 & 113.447 & 499.578 & .784 & .506 & .702 \\
\hline FI3 & 113.467 & 497.690 & .690 & .661 & .712 \\
\hline FI4 & 113.140 & 498.440 & .687 & .529 & .652 \\
\hline FI5 & $\mathbf{1 1 3 . 0 9 0}$ & $\mathbf{4 9 8 . 5 6 7}$ & .247 & .393 & .933
\end{tabular}

Appendix B: Discriminant validity (Heterotrait-Monotrait Ratio)

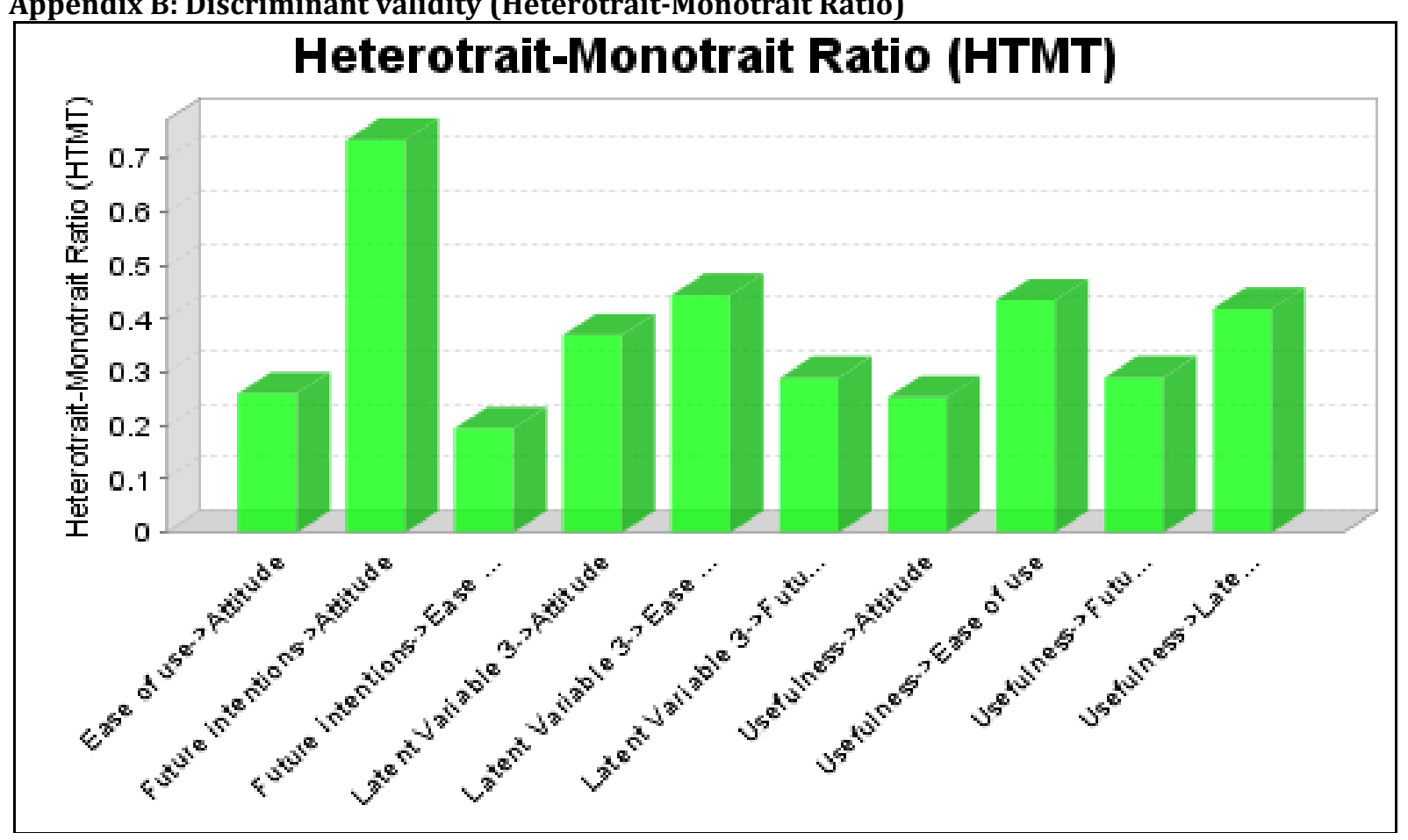

